\title{
Organochlorine accumulation on a highly consumed bivalve (Scrobicularia plana) and its main implications for human health
}

\author{
T.F. Grilo ${ }^{\text {a,* }}$, P.G. Cardoso ${ }^{\text {b }}$, P. Pato ${ }^{\text {c }}$, A.C. Duarte ${ }^{\text {c }}$, M.A. Pardal ${ }^{\text {a }}$ \\ a CFE - Centre for Functional Ecology, Department of Life Sciences, University of Coimbra, PO-BOX 3046, 3001-401 Coimbra, Portugal \\ b IMAR-CMA-Marine and Environmental Research Centre, Department of Life Sciences, University of Coimbra, 3004-517 Coimbra, Portugal \\ c Department of Chemistry, \& Center for Environmental and Marine Studies (CESAM), University of Aveiro, 3810-193 Aveiro, Portugal
}

\section{H I G H L I G H T S}

- Contamination by PCBs and HCB decreased with the distance to the pollution source.

- Deeper sediment layers presented higher PCB and HCB levels than superficial ones.

- Contamination exceeds sediment quality guidelines, inducing toxic effects in biota.

- Scrobicularia plana tended to bioaccumulate PCBs throughout its lifespan.

- Bivalves incorporate $0.4 \mathrm{~g} \cdot \mathrm{y}-1$ of PCBs from sediments, free for trophic transfer.

\section{A R T I C L E I N F O}

\section{Article history:}

Received 14 February 2013

Received in revised form 30 April 2013

Accepted 30 April 2013

Available online 29 May 2013

Editor: Adrian Covaci

\section{Keywords}

PCBs

HCB

Scrobicularia plana

Bioaccumulation

Trophic transfer

Human health

\begin{abstract}
A B S T R A C T
Contamination by polychlorinated biphenyls (PCBs) and hexachlorobenzene (HCB) was investigated along a spatial gradient in water, sediments and in commercially important bivalve species Scrobicularia plana, from Ria de Aveiro (Portugal). Organochlorines dissolved in water were below detection limit and concerning suspended particulate matter, only PCBs were quantified, ranging from 3.8 to $5.8 \mathrm{ng} \cdot \mathrm{g}^{-1} \mathrm{DW}\left(\Sigma_{13} \mathrm{PCBs}\right)$. There was a distinct spatial gradient regarding PCB accumulation in sediments. The highest concentrations were found in deeper layers and closest to the pollution source, decreasing gradually along a $3 \mathrm{~km}$ area. Contamination in sediments exceeded the Canadian and Norwegian sediment quality guidelines, inducing potential toxic effects in related biota. PCBs tended to bioaccumulate throughout S. plana lifespan but with different annual rates along the spatial gradient. The maximum values were found in older individuals up to $3+$ years old, reaching $19.4 \mathrm{ng} \cdot \mathrm{g}^{-1}$ DW. HCB concentrations were residual and no bioaccumulation pattern was evident. Congeners 138, 153 and 180 were the most accumulated due to their abundance and long-term persistence in the environment. In the inner area of the Laranjo Bay $\left(0.6 \mathrm{~km}^{2}\right)$, the species was able to remove up to $0.4 \mathrm{~g}$ of PCBs annually from sediments into their own tissues, which is consequently free for trophic transfer (biomagnification). Concerning human health, and despite the high concentrations found in sediments, PCB levels in bivalves do not exceed the limit established by the European Union for fishery products and are largely below tolerable daily intake. Although PCBs in Scrobicularia plana are present at low levels, their impact to human health after consumption over many years might be harmful and should be monitored in future studies.
\end{abstract}

(c) 2013 Elsevier B.V. All rights reserved.

\section{Introduction}

Environmental contamination by persistent organic pollutants (POPs) has received increasing concern worldwide, reflecting the impact of anthropogenic activities over time. Organochlorine compounds such as polychlorinated biphenyls (PCBs) and hexachlorobenzene

\footnotetext{
* Corresponding author. Tel.: + 351239 836386; fax: + 351239823603. E-mail address: tfgrilo@student.biologia.uc.pt (T.F. Grilo).
}

(HCB) are defined as POPs by the Stockholm Convention, which acts as a global treaty to protect human health and the environment from these chemicals (UNEP, 2001).

Ranking among the top 5 priority hazardous substances along with arsenic, lead, mercury and vinyl chloride (ATSDR, 2007), PCBs were manufactured commercially in Europe from 1929 until the mid-1980s (OSPAR, 2010) and were primarily used in industry due to their insulating and flame retardant properties. According to the Water Framework Directive (2000/60/EC), HCB is also identified as a priority hazardous substance and has been synthesized and used from the 1940s to the late 1970 s as a fungicide for a variety of crops, being also applied in 
several manufacturing processes such as aluminum and graphite rods. Although PCBs are no longer produced, hundreds of thousands of tons are still in use in electrical transformers and other equipments (Zhou et al., 2001; Otchere, 2005), giving the governments until 2025 to phase out these uses and arrange alternative PCB-free replacements (UNEP, 2001). Likewise, HCB production has now virtually ceased in Europe but it may still be released into the environment, since it is currently formed as an inadvertent by-product at trace levels in the production of chemical solvents, several pesticides and by combustion of chlorinated waste material.

Due to their toxicity, potential to bioaccumulate on fatty tissues and biomagnification through the food chain, exposure to these pollutants is a topic of huge concern (Otchere, 2005; Tomza et al., 2006). In fact, POPs have been directly related with deleterious health problems, including endocrine disruption, reproductive disorders, cardiovascular diseases, carcinogenicity and neurotoxicity (Amodio et al., 2012 and references therein).

Ria de Aveiro, a lagoon adjacent to the Atlantic Portuguese coast, comprises in its vicinity a large industrial complex besides extensive agriculture fields, in which great amounts of fertilizers and pesticides are applied. Considering the use of PCBs and HCB in industrial electrical equipment, pesticide extenders and fungicides respectively, it is crucial to determine if there exists a contamination by organochlorines in the inner part of the lagoon, the Laranjo Bay. Thus, a survey was conducted in order to investigate their occurrence along a spatial contamination gradient in water, muddy sediments and biota, specifically in the bivalve Scrobicularia plana from three selected locations of Ria de Aveiro.

As sedentary filter-feeders, bivalves are known to be effective bioaccumulators of chemical substances (Coelho et al., 2006; Lobo et al., 2010; Cardoso et al., 2012, 2013), providing a time integrated indication of environmental contamination, as well as reliable information on the potential impact of seafood consumption on public health (Fang, 2004; Otchere, 2005). The worldwide-distributed benthic bivalve $S$. plana is a deposit feeding species of high commercial interest and key importance in the structure and functioning of estuarine ecosystems. It is a crucial prey item to higher trophic levels (crabs, fishes and birds), playing an important role in biogeochemical cycles of both nutrients and contaminants, as a consequence of its bioturbation activity. This species presents a lifespan of 5 years, growth rates of $1 \mathrm{~cm} \cdot \mathrm{yr}^{-1}$ (Verdelhos et al., 2005) and has been extensively used as a relevant model organism for biomonitoring programs and toxicity tests (Coelho et al., 2006; Bonnard et al., 2009; Cardoso et al., 2012). Despite being a well-studied edible species, there is no information regarding $\mathrm{PCB}$ and $\mathrm{HCB}$ accumulation throughout its life cycle. Therefore, the major aims of this paper were: (1) to study PCB and HCB accumulation in water, muddy sediments and in the bivalve S. plana; (2) to assess the annual PCB bioaccumulation pattern during S. plana lifespan; (3) to evaluate the potential PCB transfer from contaminated sediments to economically important species; and (4) to infer about the risks for human health intrinsic to the consumption of bivalves from locations with different concentrations of PCBs and HCB.

\section{Materials and methods}

\subsection{Study area and sample collection}

The sampling campaigns were conducted in Ria de Aveiro $\left(40^{\circ} 38^{\prime} \mathrm{N}\right.$, $8^{\circ} 45^{\prime} \mathrm{W}$ ). This coastal lagoon is located in the northwestern part of Portugal (Fig. 1) and is permanently connected to the sea, receiving inputs from agriculture, urban and industrial activities. Ria de Aveiro supports a population of 250,000 inhabitants in the watershed area, and its main municipality (Aveiro town) is located $15 \mathrm{~km}$ south from an industrial complex, in which chlorine and aromatic compounds containing benzene are produced. From the 1950s until the present, Ria de Aveiro continuously receives effluents coming from this industrial complex, inducing an environmental contamination gradient inside the lagoon and most pronouncedly in the sediments of a bay named Laranjo (Coelho et al., 2006; Pereira et al., 2009). Three sampling locations were selected along a spatial contamination gradient in the Laranjo Bay, regarding the distance to the point where industrial effluents were discharged Station 1, Station 2 and Station 3 (Fig. 1).

Water, sediments and biological samples were collected in the spring of 2011, on the mudflats during low tide conditions. On each study area, water samples were collected from intertidal pools by using pre-washed glass bottles, free of organochlorine residues, and maintained on ice during transportation to the laboratory. A composite sediment sample was obtained from the upper $5 \mathrm{~cm}$, consisting of three randomly replicate cores ( $141 \mathrm{~cm}^{2}$ surface area) pooled together with the purpose to account for within-site variability. An additional composite sediment sample was obtained from a deeper layer $(15-20 \mathrm{~cm})$, with an equal number of replicates as described above, in order to examine if there were differences in organochlorine contamination according to depth. Supplementary sediment samples were taken for determination of the total organic matter (TOM) content. Sediments were previously dried at $60{ }^{\circ} \mathrm{C}$ and combusted at $500{ }^{\circ} \mathrm{C}$ for $4 \mathrm{~h}$ (Lobo et al., 2010).

S. plana individuals were collected by hand, washed in situ and transported in a thermic box. At the laboratory, individuals were left in clean seawater at $20{ }^{\circ} \mathrm{C}$ for $24 \mathrm{~h}$ to depurate, then measured in terms of total length and dissected. Afterwards, bivalve samples were freeze-dried at $-60{ }^{\circ} \mathrm{C}$ and $1.0 \mathrm{bar}$, and homogenized for later PCB extraction. Prior to the analysis, the samples were grouped into three size classes (1-2, 2-3 and 3-4 cm, corresponding to $1+, 2+$, and $3+$ year old individuals, respectively) (Verdelhos et al., 2005). Few individuals below $1 \mathrm{~cm}$ and above $4 \mathrm{~cm}$ were found for all locations, making it impossible to obtain sufficient body mass to perform organochlorine analysis and quantification in these age classes.

\subsection{Sample preparation and $P C B$ and $H C B$ extraction}

\subsubsection{Water and suspended particulate matter (SPM)}

Water samples from intertidal pools were filtered through prewashed (hexane) glass fiber filters (Whatman GF/F, Ø $47 \mathrm{~mm}$, Schleicher \& Schuell), before heating to $350{ }^{\circ} \mathrm{C}$ for $10 \mathrm{~h}$ (adapted from Antunes et al., 2007). This procedure was used in order to eliminate possible traces of organic compounds and also to separate dissolved and particulate fractions. While the dissolved fraction was collected in glass flasks and analyzed within two days, the glass fiber filters were packed into aluminum foil and stored frozen for latter suspended particulate matter (SPM) analysis. SPM samples were transferred to cellulose thimbles and Soxhlet extracted for $16 \mathrm{~h}$ with a mixture of $n$-hexane:acetone (1:1) (adapted from Antunes et al., 2007). Afterwards, resulting extracts were cleaned up following the methodology described for the sediments. Dissolved fraction samples (aliquots of $1000 \mathrm{~mL}$ ) were spiked with CB209 and extracted following the USEPA method 3510C (using hexane as extraction solvent). The extraction was repeated three times; the combined hexane extract was concentrated in a rotary evaporator and submitted to SPE cleanup in a column with Florisil (using hexane for conditioning and elution) and anhydrous sodium sulphate. After evaporation in a rotary evaporator and under a gentle nitrogen flow, the extract was stored at $-20^{\circ} \mathrm{C}$ until analysis.

\subsubsection{Sediments}

Sediment samples were freeze-dried, sieved to $<1 \mathrm{~mm}$, homogenized and wrapped in aluminum foil. Representative aliquots of $10 \mathrm{~g}$ of sediment were Soxhlet-extracted with $180 \mathrm{~mL}$ of hexane/acetone $(1: 1)$ for $8 \mathrm{~h}$, at a rate of 10 cycles/h, in a prewashed glass fiber thimble (adapted from USEPA, 1996). For both sediment and SPM resulting extracts, activated copper granules were added to remove elemental sulphur. The extracts were concentrated using a rotary evaporator 


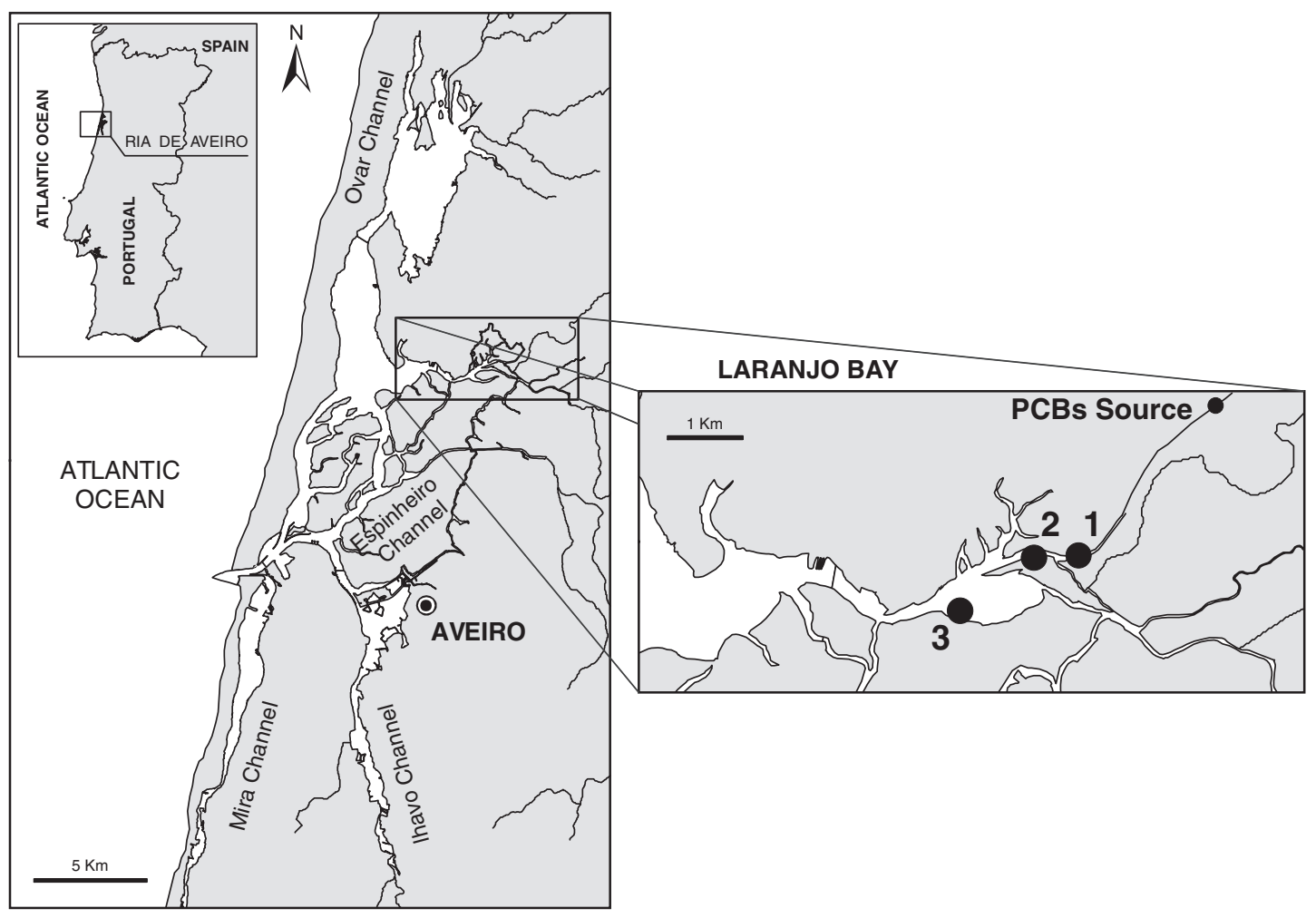

Fig. 1. The Ria de Aveiro coastal lagoon and sampling area location.

(at $30^{\circ} \mathrm{C}$ ) and submitted to a clean-up using solid-phase extraction cartridges filled with $1 \mathrm{~g}$ of silica (Supelclean ${ }^{\circledR}$ LC-Si), and $2 \mathrm{~g}$ of neutral alumina (Supelclean ${ }^{\circledR}$ LC-AL-N), both $3 \%$ deactivated, and $0.5 \mathrm{~g}$ of anhydrous sodium sulphate at the top, using a solid phase extraction (SPE) system. The elution was made with $20 \mathrm{~mL}$ of hexane/ dichloromethane $(9: 1)$ and $10 \mathrm{~mL}$ of hexane/dichloromethane (2:1). The eluate was then concentrated down to $1 \mathrm{~mL}$ using a rotary evaporator and dried under a gentle stream of nitrogen. The extracts were re-dissolved in hexane and further experienced a clean-up with $2 \mathrm{~g}$ of acidic silica ( $30 \%$ concentrated $\mathrm{H}_{2} \mathrm{SO}_{4}, \mathrm{w} / \mathrm{w}$ ), eluted with $15 \mathrm{~mL}$ of hexane and the solvent changed to iso-octane before analysis in a gas chromatographer with mass spectrometry detector (GC-MS).

\subsubsection{Bivalves}

Regarding bivalves, individuals from the same size class were homogenized and combined into a single composite, and then sub-sampled for analysis. This procedure was done in order to obtain enough body mass to accurately determine PCB concentration in bivalves. According to the mass available for each age class from distinct locations, sub-samples of $3 \mathrm{~g}$ were weighted, followed by the addition of polychlorinated CB 209 to monitor extraction efficiency. Subsequently, samples were extracted by sonication (Selecta ${ }^{\circledR}$ ) with an $n$-hexane:acetone (1:1) mixture $(30 \mathrm{~mL})$, for $20 \mathrm{~min}$. Extract was decanted and the process was repeated thrice. Solvent volume was reduced by using a rotary evaporator. Lipid content was gravimetrically determined using $10 \%$ of the extract. A soft stream of nitrogen was used to reduce solvent volume by evaporation. Lipids were removed with sulphuric acid (97\%). Afterwards, the extract passed through a multilayered column packed with Florisil $(1 \mathrm{~g}$ of Supelclean ${ }^{\circledR}$ Florisil) and anhydrous sodium sulphate, and organochlorines eluted with $15 \mathrm{~mL}$ of hexane. All samples were dried, under a gentle stream of nitrogen, and solvent exchanged to iso-octane before analysis.

\section{3. $P C B$ and $H C B$ analysis and quantification}

Before the gas chromatography coupled to mass spectrometry (GC-MS) analysis, internal standards were added (HCB- ${ }^{13} \mathrm{C}, \mathrm{CB} 34,62$, 119, 131 and 173) and the extract was reconstituted to $200 \mu \mathrm{L}$ of iso-octane for analysis. All resultant extracts (water, SPM, sediments and bivalves) were analyzed by using a gas chromatographic system (Shimadzu Corporation GC/MS-QP5050A) equipped with a ZB5-MS column (30 $\mathrm{m} \times 0.25 \mathrm{~mm}$ i.d., $0.25 \mu \mathrm{m}$ film thickness), helium as carrier gas $(0.9 \mathrm{~mL} / \mathrm{min})$ and a MS detector using electron impact ionization. Samples were injected $(1 \mu \mathrm{L})$ in splitless mode and the analytes were separated with the following oven temperature program: 2 min at $40{ }^{\circ} \mathrm{C}$, first ramp at $10{ }^{\circ} \mathrm{C} \mathrm{min}-1$ to $180{ }^{\circ} \mathrm{C}$, second ramp at $6{ }^{\circ} \mathrm{C} \mathrm{min}-1$ to $310{ }^{\circ} \mathrm{C}$ (held for $10 \mathrm{~min}$ ). The injector was operated at $280{ }^{\circ} \mathrm{C}$ and the interface at $310{ }^{\circ} \mathrm{C}$.

HCB and thirteen PCB congeners (IUPAC nos. 18, 28 and 31-tri; 44 and 52-tetra; 101 and 118-penta; 138, 149 and 153-hexa; 170 and 180-hepta and 194-octachlorobiphenyl) according to EN 12766/CEN and EN 61619 were analyzed. Within these, seven congeners were considered as priority marine pollutants by ICES (1987) and have ecological relevance (IUPAC nos. 28, 52, 101, 118, 138, 153 and 180). However, according to recent recommendations from the European Commission (Commission Regulation (EU) No., 1259/2011), only six congeners should be considered as ecological indicators ( $\left.\sum_{6} \mathrm{PCBs}\right)$, being the CB118 exclusively classified as a dioxin-like PCB (dl-PCB). Based on the latest regulations, the inclusion of $\mathrm{CB} 118$ was not considered in the results' section, specifically in PCB indicators analysis.

The detector was operated in selected ion monitoring (SIM) acquisition and the ions monitored were: 284 for $\mathrm{HCB}$ and 290 for $\mathrm{HCB}-{ }^{13} \mathrm{C}$; 256, 258 for tri-CBs; 292, 290 for tetra-CBs; 326, 328 for penta-CBs; 360, 362 for hexa-CBs; 394, 396 for hepta-CBs; and 430, 428 for octa-CBs. The ions highlighted in bold were used for quantification and the others for confirmation. Besides the confirmation ions, the 
identifications of PCB congeners were also made on the basis of their retention times relative to the internal standards.

\subsection{Quality assurance and quality control $(\mathrm{QA} / \mathrm{QC})$ procedures}

The method performance was assessed by a daily check of calibration curves, method blanks, analysis of certified reference materials (CRMs), fortification of samples and recoveries of surrogate ( $C B$ 209). Method blanks were done in every forth sample in order to detect possible interferences from the reagents, glassware and other processing hardware. In fortified water samples recoveries varied between 78 and $104 \%$ and in sample recoveries of CB209 were $82 \pm 5 \%$ (95\% confidence interval). The PCB recoveries for the sediment CRM CNS-300 (freshwater sediment) ranged between 83\% and 99\% and for the CRM-141 (freshwater sediment) recoveries ranged between $81 \%$ and $110 \%$ for PCBs and HCB. For spiked sediment samples, analyte recoveries were between 74 and 105\%. The results of PCBs in the NIST certified material SRM 2977 (mussel tissue) were within 74-108\% of the certified values and in spiked bivalve samples the recoveries of analytes ranged from 78 to $112 \%$. Both for sediments and biota, surrogate recoveries ranged from $68 \%$ to $115 \%$. Limits of detection for individual congeners and $\mathrm{HCB}$ ranged between 0.6 and $0.8 \mathrm{ng} \cdot \mathrm{L}^{-1}$ in water, from 0.3 to $1.4 \mathrm{ng} \cdot \mathrm{g}^{-1}$ in SPM samples, from 0.04 to $0.10 \mathrm{ng} \cdot \mathrm{g}^{-1}$ in sediments and from 0.15 to $0.40 \mathrm{ng} \cdot \mathrm{g}^{-1}$ in bivalves.

\subsection{Secondary production}

Secondary production is a useful tool of ecosystem function, representing a direct measure of food provision delivered by an ecosystem, with a clear socioeconomic value. Calculation of secondary production was performed by using data obtained by monthly sampling campaigns undertaken from September 2010 to September 2011 in the same locations. Secondary production was estimated using the Brey (2001) method version 4-04 (worksheet provided in Brey, 2001; www.awi-bremerhaven.de/Benthic/Ecosystem/FoodWeb/ Handbook/main.htm), considered the best alternative empirical method to estimate secondary production (Dolbeth et al., 2005, 2011). No value was given to the depth, since the species is intertidal and conversions from ash-free dry weight (AFDW) to dry weight (DW) were done based on Dolbeth et al. (2005). Determination of the annual production of S. plana, will allow to estimate the quantity of PCBs removed from the sediments (otherwise not bioavailable), and consequently free for trophic transfer to predators. This quantification is essential to evaluate the amount of PCBs that could reach higher trophic levels endangering the aquatic environment.

\subsection{Bioaccumulation and biota-sediment accumulation factors}

The partitioning of compounds between the organisms and abiotic environmental compartments, in which they inhabit may be described by the bioaccumulation factor (BAF). Since this study aimed to measure PCBs in different layers of the sediment profile, it was assumed that the use of the mean value of PCB concentration between superficial and deeper layers for calculation of BAF was more appropriate. In addition, because the HCB concentration in bivalves was mostly below the detection limit, it was only possible to calculate BAF for PCBs, according to the formula (Lee, 1992; Lobo et al., 2010):

$\mathrm{BAF}=\frac{C_{0}}{C_{s}}$

where $C_{o}$ represents the $\mathrm{PCB}$ concentration in the organism expressed in $\mathrm{ng} \cdot \mathrm{g}^{-1}$ dry weight of tissue and $C_{S}$ is the PCB concentration in the sediment expressed in $\mathrm{ng} \cdot \mathrm{g}^{-1}$ dry weight of sediment. Biotasediment accumulation factors (BSAFs) were also calculated and are essentially the BAF normalized to the total organic matter content of the sediment (TOM, given in \% relative to sediment DW) (adapted from USEPA, 1995; Lobo et al., 2010):

$\mathrm{BSAF}=\frac{C_{0}}{\left(C_{S} / \mathrm{TOM}\right)}$

\subsection{Statistical analysis}

All data were initially checked for normality and for homogeneity of variances using Shapiro-Wilk's and Bartlett's tests respectively (Zar, 1996). Data not meeting these criteria were transformed appropriately and checked again for normality and homoscedasticity (Zar, 1996). Differences in PCB and HCB concentrations between stations and sediment depths were analyzed with a multivariate two-way ANOVA (stations $\times$ depths). A similar statistical methodology was used to determine differences in PCB concentrations between study areas and bivalves' age classes. Pairwise multiple comparisons (stations, sediment depths and S. plana age classes) were made using Tukey's honestly significant difference (HSD) test, except whenever the number of replicates differed among bivalves' age classes of different stations. In this case, the Unequal N HSD was applied. This test is a modification of Tukey's HSD test and provides an acceptable test of differences in group means if group ns are not too discrepant (Winer et al., 1991). All statistical analyses were performed with Statistica 7 software (StatSoft).

\section{Results}

\subsection{Organochlorines in water, SPM and sediments}

Levels of PCBs and HCB in water of the three sampling locations were vestigial and below the limit of detection (LOD), never exceeding $0.80 \mathrm{ng} \cdot \mathrm{L}^{-1}$ for all analyzed congeners. All suspended particulate matter (SPM) samples presented also HCB levels below detection limit. Concentrations of PCBs in SPM samples were low ranging between $3.77 \pm 0.43 \mathrm{ng} \cdot \mathrm{g}^{-1} \mathrm{DW}$ in Station 3 (sum of CBs 138 and 153) and $5.84 \pm 0.52 \mathrm{ng} \cdot \mathrm{g}^{-1} \mathrm{DW}$ in Station 1 (sum of CBs 101, 138, 149 and 153).

PCB accumulation in sediments showed a distinct spatial gradient, with Station 1 presenting significantly much higher contamination than the remaining areas (two-way ANOVA: $F_{2,11}=183.1, p<0.001$ ) (Fig. 2). In addition, there were statistical differences in PCB concentrations according to depth (two-way ANOVA: $F_{1,11}=391.3, p<0.001$ ) and a significant interaction was also found between factors (stations $\times$ depths) (two-way ANOVA: $F_{2,11}=136.5, p<0.001$ ). Sediment superficial layers $(0-5 \mathrm{~cm})$ of Stations 1 and 2 presented similar PCB content, below $5 \mathrm{ng} \cdot \mathrm{g}^{-1} \mathrm{DW}$ (Fig. 2A,B), while superficial deposits of Station 3 had approximately half of that concentration (Fig. 2C). However, no relevant statistical differences were found (Tukey's test, $p>0.05$ ). Concerning PCB concentrations in the deepest strata (15$20 \mathrm{~cm}$ ), it was observed that sediments from Station 1 were 4 and 17 times more contaminated than those from Stations 2 and 3, respectively (Tukey's test, $p<0.05$ ). Congener composition analysis showed that CBs 153, 138 and 180 were the most abundant, independent from the sampling station and/or the depth, accounting for $50 \%$ of the total studied congeners. On the other hand, trichlorobiphenyl congeners $(18,28$ and 31) were very rare, except in deeper sediments from Station 2 in which the CB18 was the third most represented (Fig. 2B). The octachlorobiphenyl CB194 was not detected in superficial sediments from the three selected locations and in the less contaminated site, it was even undetectable in the 15-20 cm depth (Fig. 2C).

Distribution of HCB in sediments followed a similar tendency described for PCBs (Table 1), despite values being substantially smaller. Significant statistical differences were observed between stations (two-way ANOVA: $F_{2,11}=27.0, p<0.001$ ) and sediment depths 

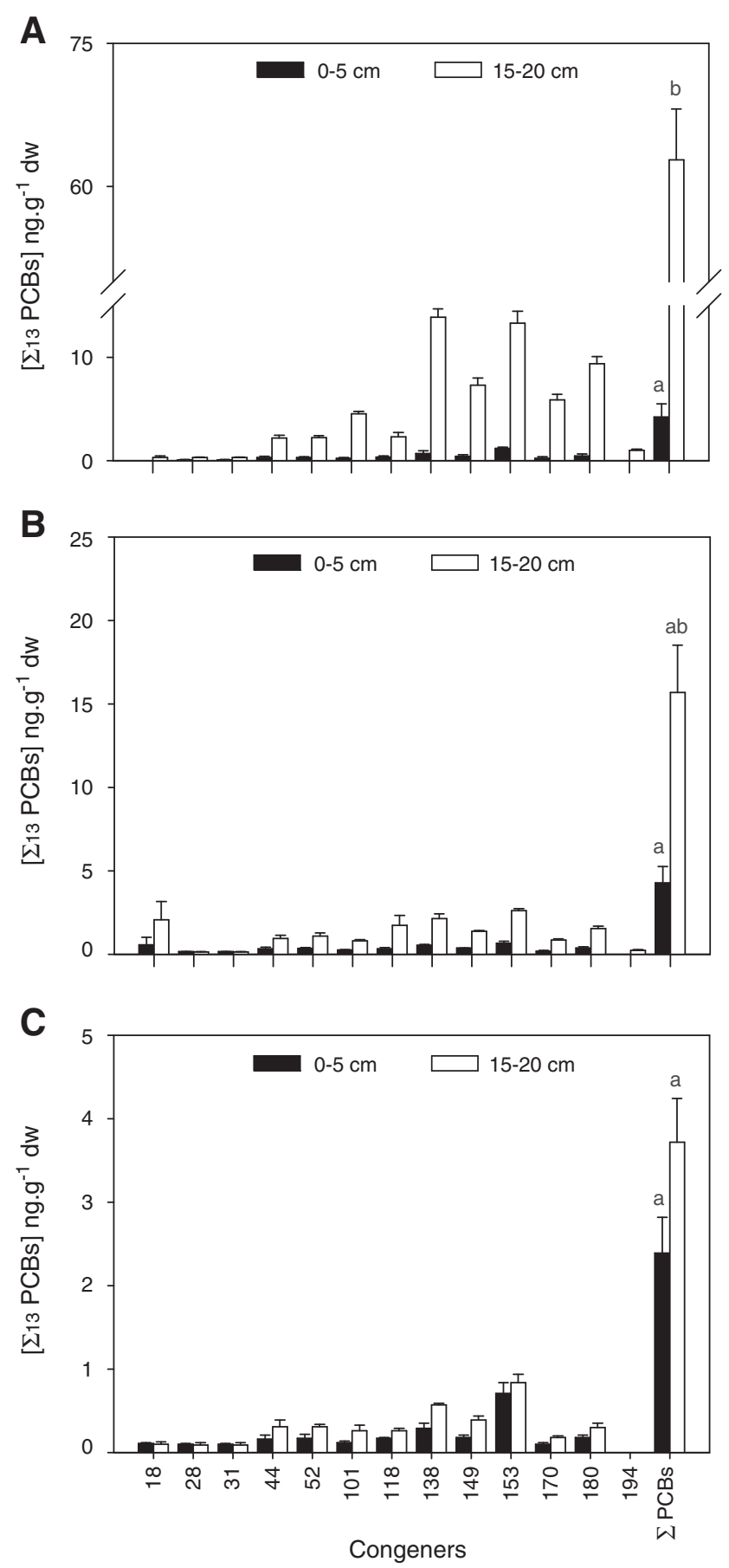

Fig. 2. Mean $\Sigma_{13} P C B$ concentrations (ng $\cdot \mathrm{g}^{-1}$ dry weight) at distinct sediment depths (in centimeters) from different sampling locations: (A) Station 1; (B) Station 2; and (C) Station 3. Error bars represent standard error. Tukey's test results are presented: different letters indicate significant differences among treatments $(p<0.05)$.

(two-way ANOVA: $F_{1,11}=33.5, p<0.001$ ). The highest concentrations were reported nearby the industrial complex, decreasing steadily along a $3 \mathrm{~km}$ gradient. Deeper sediment layers contained higher HCB levels, except in Station 3 where contamination was vestigial and no differences in HCB concentration were recognized along sediment depth profile.

\subsection{Organochlorines in S. plana}

In accordance with the spatial gradient described for the sediments, the bivalves from the station closer to the point of discharge
Table 1

$\mathrm{HCB}$ concentration (ng $\cdot \mathrm{g}^{-1}$ dry weight) at distinct sediment depths (in centimeters) and different age classes of the bivalve S. plana (mean \pm SE). Tukey's test results are presented: different letters indicate significant differences among treatments $(\mathrm{p}<0.05)$.

\begin{tabular}{cllllll}
\hline Location & $\begin{array}{l}\text { Sediment } \\
\left(\mathrm{ng} \cdot \mathrm{g}^{-1} \mathrm{DW}\right)\end{array}$ & & \multicolumn{2}{l}{$\begin{array}{l}\text { Scrobicularia plana } \\
\left(\mathrm{ng} \cdot \mathrm{g}^{-1} \mathrm{DW}\right)\end{array}$} \\
\cline { 2 - 3 } & $0-5$ & $15-20$ & & $1+$ & $2+$ & $3+$ \\
\hline Station 1 & $3.79 \pm 2.03^{\mathrm{a}}$ & $9.49 \pm 0.31^{\mathrm{b}}$ & & bdl & $0.312 \pm 0.028$ & $0.316 \pm 0.026$ \\
Station 2 & $2.00 \pm 0.16^{\mathrm{a}}$ & $5.89 \pm 0.58^{\mathrm{a}}$ & & bdl & $0.234 \pm 0.002$ & $0.178 \pm 0.011$ \\
Station 3 & $0.25 \pm 0.05^{\mathrm{a}}$ & $0.23 \pm 0.02^{\mathrm{a}}$ & & bdl & bdl & $0.151 \pm 0.046$ \\
\hline
\end{tabular}

bdl - below detection limit (<LOD).

of industrial effluents evidenced higher contamination, decreasing significantly with the distance to the PCB source (two-way ANOVA: $F_{2,10}=6.3, p<0.05$ ) (Fig. 3A). Likewise, when the considered PCB concentration was expressed in a lipid weight basis, an identical spatial gradient emerged (Fig. 3B). In average, individuals from Station 1 presented twice the lipid normalized PCB concentration than the ones inhabiting the moderately contaminated area and 2.5 times more PCBs than bivalves from the less contaminated area. For all locations, smaller individuals presented lower contamination values, while larger bivalves tended to progressively accumulate higher levels, suggesting a bioaccumulation trend throughout $S$. plana lifespan (Fig. 3A,B). Moreover, PCB concentration varied significantly between age classes (two-way ANOVA: $F_{2,10}=10.4, p<0.05$ ) and no interaction between study areas and age classes was detected (two-way ANOVA: $F_{4,10}=1.0, p>0.05$ ).
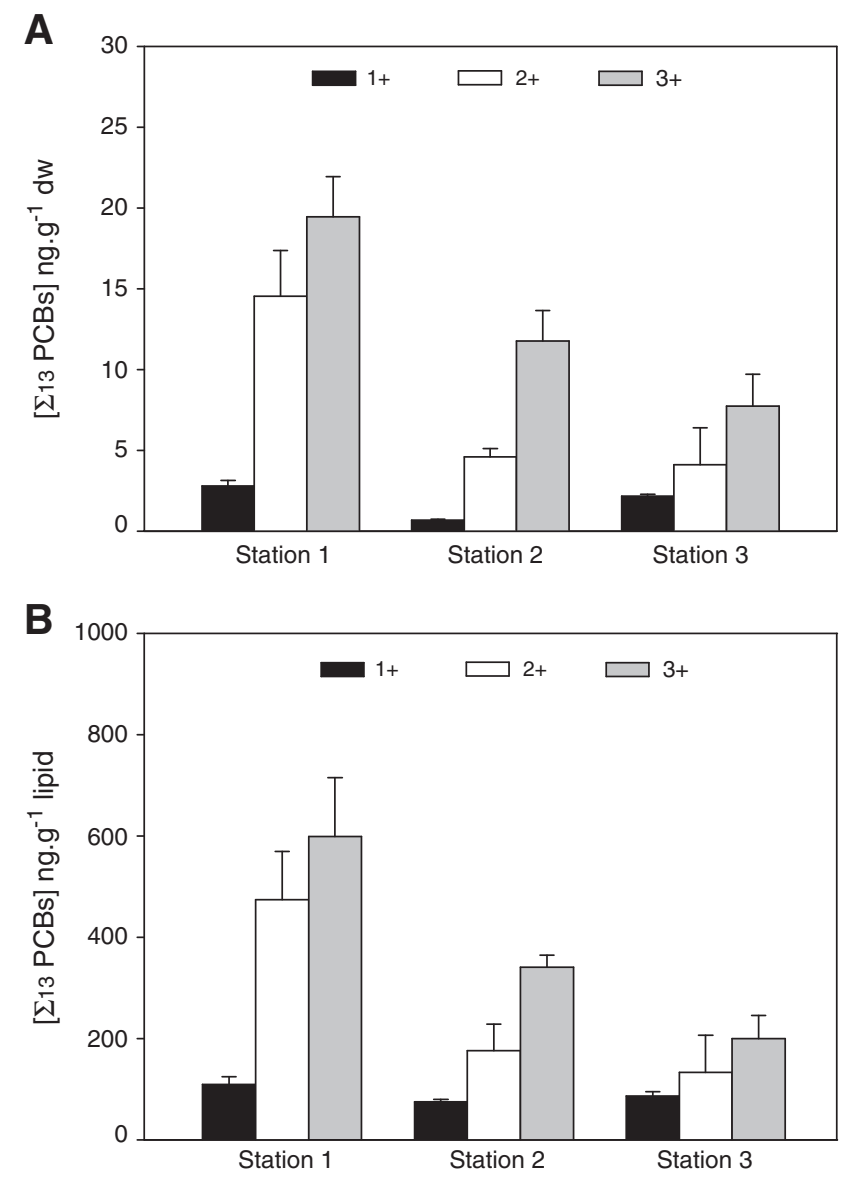

Fig. 3. Mean $\Sigma_{13} \mathrm{PCB}$ concentrations in different age classes of $S$. plana from distinct sampling locations: (A) expressed in $\mathrm{ng} \cdot \mathrm{g}^{-1}$ dry weight; and (B) expressed in a lipid weight basis ( $\mathrm{ng} \cdot \mathrm{g}^{-1}$ lipid). Error bars represent standard error. 
Analysis of the six congeners with ecological relevance $\left(\Sigma_{6} \mathrm{PCBs}\right)$ showed a well-defined bioaccumulation pattern during $S$. plana lifespan, common to all sampling locations (Fig. 4). The single ecological congener detected in bivalves grouped into the class $1+$ was CB153, however with age, five remaining indicator congeners tended to be gradually accumulated. Data revealed that the most represented and incorporated congeners by the bivalves were CBs 153, 138 and 52 , which is consistent with results obtained for the sediments, except for the latest congener. Within this group of six congeners, CB28 was not detected in bivalves from Station 3 (Fig. 4C) and accounted for less than $1 \%$ in the two most contaminated areas, being only detected in individuals larger than $2 \mathrm{~cm}$ (Fig. 4A,B).

For all sampling areas, no HCB residues were detected $(<\mathrm{LOD})$ in the smallest bivalves. In the less contaminated area it was only possible to quantify $\mathrm{HCB}$ in individuals larger than $3 \mathrm{~cm}$. Contamination levels were quite lower and almost negligible compared to PCBs. Also, a bioaccumulation trend during S. plana lifespan was not evident (Table 1).
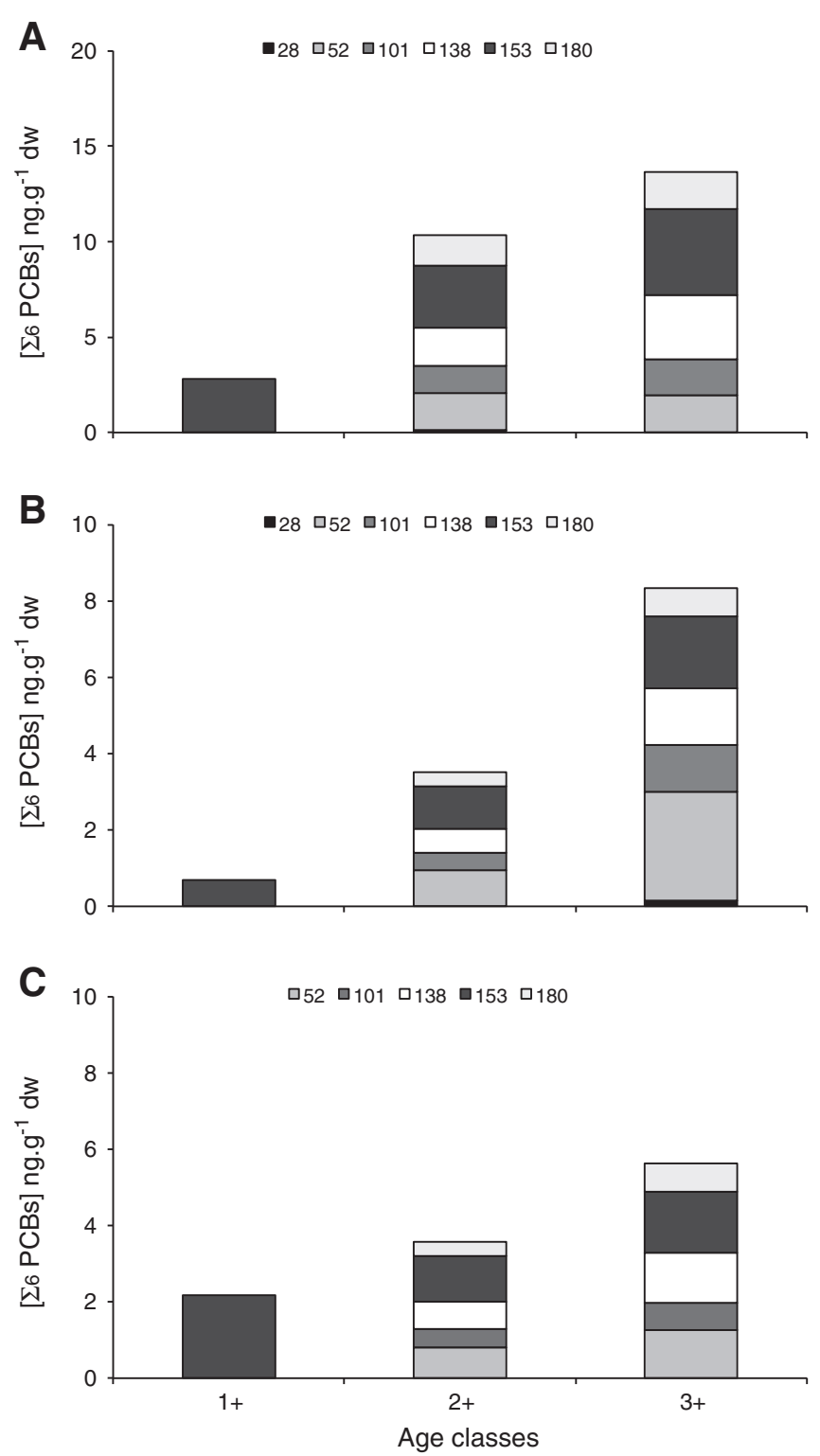

Fig. 4. Mean $\Sigma_{6} \mathrm{PCB}$ concentrations (ng $\cdot \mathrm{g}^{-1}$ dry weight) in different age classes of S. plana, along a spatial contamination gradient: (A) Station 1; (B) Station 2; and (C) Station 3.

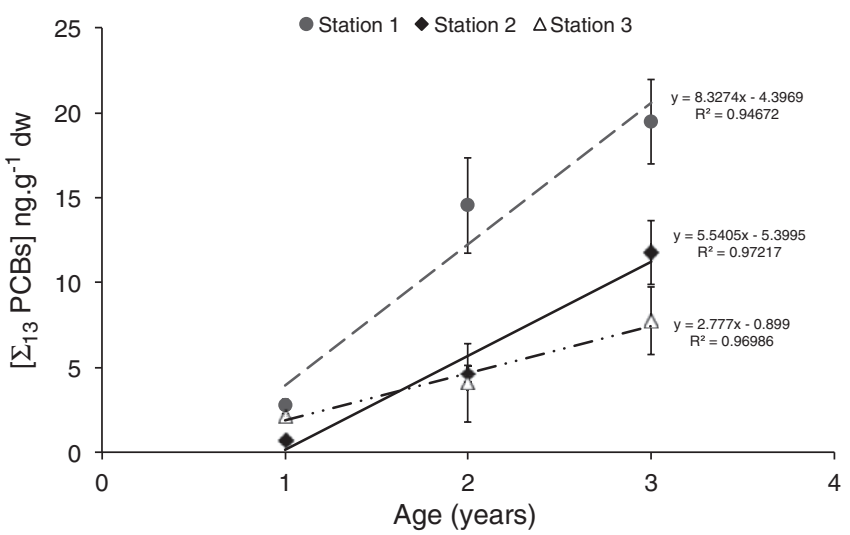

Fig. 5. PCB accumulation during S. plana lifespan. The trendlines calculated from average levels correspond to the annual net accumulation of PCBs by bivalves for each sampling location. Error bars represent standard error.

3.3. Annual rates of PCB bioaccumulation, secondary production, transfer to the trophic chain and biota-sediment accumulation factors

Annual PCB bioaccumulation rates through S. plana lifespan varied differently in result to the environmental organochlorine levels. Bioaccumulation followed a linear trend in all locations, with annual rates increasing with the proximity to the pollution source (Fig. 5). In the most contaminated station $\left(8.3 \mathrm{ng} \cdot \mathrm{g}^{-1} \cdot \mathrm{yr}^{-1}\right)$, the annual bioaccumulation rate was 1.5 times greater than the estimated rate for the intermediate station ( $5.5 \mathrm{ng} \cdot \mathrm{g}^{-1} \cdot \mathrm{yr}^{-1}$ ) and approximately 3 times higher than the estimated rate for the station farther away from the contamination source $\left(2.8 \mathrm{ng} \cdot \mathrm{g}^{-1} \cdot \mathrm{yr}^{-1}\right)$.

In order to assess the role of S. plana on the PCB transfer to the estuarine food webs, the annual production of this benthic sediment dwelling invertebrate was calculated in the three selected locations. Production was considerably higher in the moderately and less contaminated stations $\left(155 \mathrm{~g} \cdot \mathrm{DW} \cdot \mathrm{m}^{-2} \cdot \mathrm{yr}^{-1}\right.$ and $147 \mathrm{~g} \cdot \mathrm{DW} \cdot \mathrm{m}^{-2} \cdot \mathrm{yr}^{-1}$, respectively), while in the most contaminated area the annual production was roughly half of those values (Table 2). Considering the annual bioaccumulation rates, this bivalve was responsible for the bulk PCB removal from the sediment, incorporating almost $1 \mu \mathrm{g} \cdot \mathrm{m}^{-2} \cdot \mathrm{yr}^{-1}$ in the moderately contaminated station (Table 2 ). Three kilometers away from the effluent discharge point, such PCB removal declined 50\%. In fact, extrapolating the results from the mean associated PCBs in the three sampling locations to the approximate $0.6 \mathrm{~km}^{2}$ of intertidal flats existing in the inner Laranjo Bay, this species is responsible for the annual incorporation of almost $0.4 \mathrm{~g}$ of PCBs from the sediments.

Regarding bioaccumulation and biota-sediment accumulation factors, a common increasing tendency farther from the contamination source and through S. plana lifespan was discernible (Table 2), meaning that higher BAF and BSAF were registered in lower PCB contaminated environmental sites and in larger bivalves.

Table 2

Annual production, quantity of PCBs available for trophic transfer and bioaccumulation and biota-sediment accumulation factors in S. plana.

\begin{tabular}{|c|c|c|c|c|c|c|c|c|}
\hline \multirow[t]{2}{*}{ Location } & \multirow{2}{*}{$\begin{array}{l}\text { Annual } \\
\text { production } \\
\left(\mathrm{g} \cdot \mathrm{DW} \cdot \mathrm{m}^{-2} \text {. }\right. \\
\left.\mathrm{yr}^{-1}\right)\end{array}$} & \multirow{2}{*}{$\begin{array}{l}\text { Associated } \\
\text { PCBs } \\
\left(\mathrm{ng} \cdot \mathrm{m}^{-2} \text {. }\right. \\
\left.\mathrm{yr}^{-1}\right)\end{array}$} & \multicolumn{3}{|l|}{$\mathrm{BAF}$} & \multicolumn{3}{|c|}{ BSAF } \\
\hline & & & $1+$ & $2+$ & $3+$ & $1+$ & $2+$ & $3+$ \\
\hline Station 1 & 78 & 650 & 0.1 & 0.4 & 0.6 & 0.7 & 3.5 & 4.7 \\
\hline Station 2 & 155 & 851 & 0.1 & 0.5 & 1.2 & 0.5 & 3.4 & 8.6 \\
\hline Station 3 & 147 & 411 & 0.7 & 1.4 & 2.7 & 5.6 & 10.6 & 20.0 \\
\hline
\end{tabular}




\section{Discussion}

The assessment of organochlorine contamination in abiotic and biotic environmental compartments of the Laranjo Bay, in Ria de Aveiro, revealed that the highest concentrations were found closer to the site where industrial effluents were discharged, decreasing sharply along a $3 \mathrm{~km}$ extent area. Concentrations found in intertidal water pools were negligible and below the detection limit for both PCBs and HCB. For numerous aquatic systems across the world, PCB levels in the dissolved phase were vestigial, except in the Seine Estuary (France) and particularly in Daya Bay (China), where high concentrations were reported (Table 3). Residual levels of HCB in water were also documented in the Black Sea (Maldonado and Bayona, 2002), never exceeding $0.022 \mathrm{ng} \cdot \mathrm{L}^{-1}$. The results obtained in the Laranjo Bay concerning levels of organochlorines dissolved in intertidal water were in a certain way expected, based on the hydrophobic nature of these pollutants. In fact, PCBs easily volatilize from water surfaces in spite of their low vapor pressure, and partly as a result of their hydrophobicity (Ritter et al., 1995).

Due to that intrinsic property, these contaminants have great affinity with particulate materials, remaining strongly adsorbed to suspended particulate matter (SPM). PCB concentrations found in particulate fractions of the Laranjo Bay intertidal water were similar to those found in East Java, Indonesia (Hillebrand et al., 1989) and within the range determined by Chen et al. (2011) in Pearl River Estuary, in China (Table 3). Several European and Asian aquatic systems presented substantially lower PCBs in SPM than the Laranjo Bay and in some locations, like Daya Bay (China), no congeners were even quantified. On the other hand, values documented in the Seine Estuary were remarkably higher compared to the range estimated in the present study (Table 3). PCB levels found in SPM were slightly higher than the concentrations measured in superficial sediments, which may be related with the transport of particles from the upstream more contaminated areas to the Laranjo Bay and also with plankton's ability to bioaccumulate PCBs (Quental et al., 2003). Furthermore, preferential accumulation of PCBs with fine sediment fractions $(<63 \mu \mathrm{m})$ (Piérard et al., 1996), which remain suspended in the water column for a longer time compared to coarser particles, could also explain these results.

Sediment analysis constitutes a tool of extreme importance in aquatic ecosystem quality assessment, since sediments can reflect long-term contamination levels, acting as reservoirs and thus a source of contamination to benthic organisms (Fang, 2004; He et al., 2006). Chemistry of bottom sediments is influenced by numerous natural and anthropogenic variables and their heterogeneity and spatial variation are undoubtedly linked to erosion phenomena, transport and deposition, granulometry and organic matter content. The latter is particularly relevant in the context of accumulation of hydrophobic organic contaminants since it represents a factor directly influencing the concentration of PCBs in bottom sediments. For instance, Tomza et al. (2006) stated that sediments rich in organic matter (muddy deposits) accumulated more PCBs than sandy ones.

An increase in PCB and HCB concentrations was observed in the sediment depth profile. By analyzing organochlorines in deeper strata, a large discrepancy was found in relation to the superficial sediments, particularly in the two most contaminated sites. Deeper layers presented much higher concentrations than the uppermost sediments, reflecting PCB and HCB past emissions. Several activities related with agro-industrial development undertaken in the past may be responsible for the observed increase in the sediment core. Nevertheless, the lower levels obtained in the superficial sediments may indicate that the influence of organochlorine compounds in the study area is now decreasing. Compared to other systems worldwide, the results obtained in Ria de Aveiro regarding PCBs in sediments were identical to those found in the coast of Barcelona (Castells et al., 2008), but quite superior to those in Singapore's coast (Wurl and Obbard, 2006)

Table 3

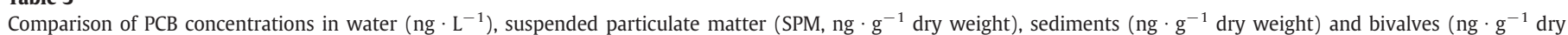
weight) from various aquatic systems worldwide.

\begin{tabular}{|c|c|c|c|c|c|c|}
\hline \multirow[t]{2}{*}{ Location } & \multirow[t]{2}{*}{ No. of CBs } & \multicolumn{4}{|l|}{$\Sigma \mathrm{PCBs}$} & \multirow[t]{2}{*}{ Reference } \\
\hline & & Water & SPM & Sediment & Bivalves & \\
\hline \multicolumn{7}{|l|}{ Africa } \\
\hline Egyptian Red Sea coast & 7 & & & & $6.7-66.4^{\mathrm{a}}$ & Khaled et al. (2004) \\
\hline Algiers Bay, Algeria & $17 / 7$ & $4.0-18.8$ & & & $64-222$ & Fouial-Djebbar et al. (2011) \\
\hline \multicolumn{7}{|l|}{ Asia } \\
\hline Manila Bay, Philippines & 13 & & & $0.1-1.5$ & $7-73$ & Villeneuve et al. (2010) \\
\hline Daya Bay, China & 12 & $91-1355$ & bdl & $0.85-27.4$ & & Zhou et al. (2001) \\
\hline Chinese Bohai Sea & 25 & & & & $1.84-3.75$ & Wang et al. (2008) \\
\hline Pearl River Estuary, China & 12 & $0.02-7.18$ & $0.02-15^{c}$ & & & Chen et al. (2011) \\
\hline Pearl River Delta, China & - & & & $16.4-198.6$ & $41-729^{b}$ & Fang (2004) \\
\hline Ya-Er Lake, China & 9 & & & $10.7-5970$ & & Wu et al. (1997) \\
\hline East Java, Indonesia & - & $0.2-3.5$ & 4 & & & Hillebrand et al. (1989) \\
\hline Singapore's Coast & 38 & $0.06-6.9$ & $0.04-3.8^{c}$ & $0.6-1.3$ & & Wurl and Obbard (2006) \\
\hline \multicolumn{7}{|l|}{ Europe } \\
\hline Danube Estuary, Romania & 10 & $0.02-0.1$ & $0.002-0.06^{c}$ & & & Maldonado and Bayona (2002) \\
\hline Odra River, Poland & 7 & $1.4-3.1$ & & $2.6-17.9$ & $33-66^{\mathrm{b}}$ & Tomza et al. (2006) \\
\hline Svalbard, Norway & 16 & & & & $55.4-78.1^{\mathrm{b}}$ & Vieweg et al. (2012) \\
\hline Gulf of Bothnia, Sweden & 12 & & & $9.0-9.3$ & & Strandberg et al. (2000) \\
\hline Seine Estuary, France & 8 & $2.0-21.2$ & $58-463$ & & & Cailleaud et al. (2007) \\
\hline Arrone River, Rome & 58 & $6-13$ & & 11-196 & & Bazzanti et al., 1997 \\
\hline Coast of Barcelona, Spain & 12 & & & $2.3-44.0$ & & Castells et al. (2008) \\
\hline Galician Coast, Spain & 10 & & & & $0.62-107.5^{\mathrm{a}}$ & Carro et al. (2010) \\
\hline Sado Estuary, Portugal & 18 & & & $1.2-17.6$ & & Lobo et al. (2010) \\
\hline Ria de Aveiro, Portugal & 13 & bdl & $3.8-5.8$ & $2.4-62.8$ & $\begin{array}{l}1.0-19.4 \\
0.1-2.3^{\mathrm{a}} \\
75.3-599.0^{\mathrm{b}}\end{array}$ & Present study \\
\hline
\end{tabular}

bdl - below detection limit (<LOD).

a $\mathrm{ng} \cdot \mathrm{g}^{-1}$ wet weight.

b $\mathrm{ng} \cdot \mathrm{g}^{-1}$ lipid weight.

c $\mathrm{ng} \cdot \mathrm{L}^{-1}$. 
or in Manila Bay, in Philippines (Villeneuve et al., 2010) (Table 3). Besides, HCB levels were similar to those reported by Kim et al. (2009) in surface sediments from the Han River, in Korea, and rather higher than levels found in the Gulf of Bothnia (Strandberg et al., 2000). Although, when compared to the Ya-Er Lake, China, where PCB concentrations in sediments reached almost $6000 \mathrm{ng} \cdot \mathrm{g}^{-1} \mathrm{DW}$ and HCB levels up to $58,000 \mathrm{ng} \cdot \mathrm{g}^{-1} \mathrm{DW}$, the results in the Laranjo Bay seemed almost irrelevant (Table 3). The Tagus Estuary, in Portugal, displayed PCB values (17.7 $\left.\mathrm{ng} \cdot \mathrm{g}^{-1} \mathrm{DW}\right)($ IAEA/MEL/67, 1999) analogous to those found in sediments from the intermediate sampling station, while contamination in the Mondego Estuary was residual, varying in the range of $0.81-2.36 \mathrm{ng} \cdot \mathrm{g}^{-1} \mathrm{DW}$ (Baptista et al., 2013).

Canadian sediment quality guidelines (CCME, 2002) can be used to assess the degree to which adverse biological effects are likely to occur as a consequence of exposure to PCBs in sediments. The present study revealed that concentrations detected in most contaminated sediments exceeded the PCB threshold effect level (TEL), $21.5 \mathrm{ng} \cdot \mathrm{g}^{-1}$, but were below PCB probable effect level (PEL), $189 \mathrm{ng} \cdot \mathrm{g}^{-1}$. Therefore, this location may be considered a highly stressful environment, since PCB toxic effects may occur on benthic biota at this contamination level, which is reflected by its lowest annual production. In fact, the bivalve Cerastoderma edule, was found to regulate and eliminate organic contaminants under adverse conditions by synthesis of metallothioneins (Lobo et al., 2010). A similar physiological response might be expected regarding the species S. plana. According to the Norwegian sediment quality guideline (NSQG; Bakke et al., 2010) for PCBs, sediments closest to the contamination source are included in class III, causing toxic effects to biota following chronic exposure. Based on NSQG, HCB levels in sediments from the Laranjo Bay were not problematic, since no toxic effects were suggested. Furthermore, according to the Portuguese Legislation for Dredged Material (Decreto-Lei no. 226-A/2007, 31 May; Portaria no., 1450/2007, 12 November), sediments collected nearby the point of discharge of industrial effluents are classified as slightly contaminated for both PCBs and HCB (25-100 ng $\cdot \mathrm{g}^{-1}$ and $2.5-10 \mathrm{ng} \cdot \mathrm{g}^{-1}$ respectively) and in the case of immersion of the dredged sediments it requires a thorough study about the deposition of local and subsequent monitoring.

Regarding the contribution of individual congeners to $\Sigma_{13}$ PCBs in sediments and bivalves, the most abundant were generally the hexa(CBs 138 and 153) and heptachlorinated (CB180) followed by the pentachlorinated ones (CBs 101 and 118), which is in accordance with observations reported by Strandberg et al. (2000), Wurl and Obbard (2006) and Villeneuve et al. (2010). That contribution was primarily related to their abundant release into the environment associated to its lower volatility (Ritter et al., 1995) and higher long-term environmental persistence compared to less chlorinated congeners.

The bivalve $S$. plana was found to respond to the human induced PCB gradient, by incorporating organic compounds parallel to environmental contamination levels. Through its filter and deposit feeding strategies, S. plana accumulated contaminants adsorbed in particulate matter (Coelho et al., 2006) and the bottom sediment. The species revealed to be an important vehicle of PCB transference from sediments to the trophic web, incorporating into their tissues; approximately $0.4 \mathrm{~g}$ of PCBs, annually, in the inner area of the Laranjo Bay $\left(0.6 \mathrm{~km}^{2}\right)$. This amount may seem residual and irrelevant, but considering that it can be transferred to higher trophic levels by predation and exported to other areas of the system, it may be significant, since this species represents an important prey item to estuarine predators such as crabs, fishes, and birds. Therefore, the importance of these findings to the understanding of biomagnification processes is evident.

Bioaccumulation and biota-sediment accumulation factors increased farther from the pollution source and in lower environmental contaminated areas. In average, levels of PCBs in sediments from Station 1 are 3 and 10 times higher than values observed in Stations 2 and 3 , respectively. However, in average, bivalves collected closer to the PCB source only reached accumulations twice the levels found in the less contaminated sites. This means that accumulation is not proportional and bivalves under higher environmental contamination demonstrated lower ability to accumulate PCBs, suggesting the eventual existence of detoxification strategies in the most contaminated area. Similar observations were reported by Lobo et al. (2010) investigating trace metal and organic compound bioaccumulation potential in the edible cockle C. edule and also by Cardoso et al. (2013) evaluating mercury bioaccumulation kinetics in the same species.

Comparisons of PCB concentrations in biota among different aquatic systems are typically difficult and require particular attention, because there is a wide variation in the number of quantified congeners and the basis in which the concentration is expressed may also vary (wet weigh, dry weight and lipid weight) (Table 3 ). For instance, in a lipid basis, results from the Laranjo Bay were comparable to PCB concentrations found in mussels Perna viridis, in South China (Fang, 2004). Moreover, S. plana accumulated higher PCB concentration than the blue mussel Mytilus edulis and the oyster Crassostrea talienwhanensis from the Chinese Bohai Sea (Wang et al., 2008), even though the number of quantified congeners between locations was different (13 CBs in this study against $25 \mathrm{CBs}$ in Chinese Bohai Sea). Using different Arctic bivalve species and analyzing $16 \mathrm{CBs}$, Vieweg et al. (2012) reported lower lipid normalized concentrations than levels obtained in the Laranjo Bay, as well as Tomza et al. (2006) investigating the uptake of 7 CBs in freshwater mussel Anodonta complanata, in Poland. On the other hand, there are numerous aquatic systems around the world in which PCB concentrations in bivalves broadly exceed levels observed in the Laranjo Bay. For example, in Mytilus galloprovincialis from the Galician coast, Carro et al. (2010) estimated PCB concentrations (wet weight) up to 50 times the maximum concentration found in S. plana. Similar observations were documented in mussels from the Egyptian Red Sea coast (Khaled et al., 2004) and from Algiers Bay (Fouial-Djebbar et al., 2011). The latter stated an evident tendency of PCB bioaccumulation along different size classes of $M$. galloprovincialis, with larger mussels $(>8 \mathrm{~cm})$ presenting higher concentrations than the small ones. Similar observations were found in S. plana throughout its lifespan, which is confirmed by $\Sigma_{13} \mathrm{PCBs}$ and also when it was only considered the contribution of the six ecological indicator congeners ( $\left.\Sigma_{6} \mathrm{PCBs}\right)$.

At present the non-dioxin-like PCBs (ndl-PCBs) lack international evaluation, and hence a health-based maximum intake level has not been established. The sum of the six indicator congeners (CBs 28, 52, $101,138,153$, and 180) comprises about $50 \%$ of the amount of total ndl-PCBs present in feed and food, being considered by the European Food Safety Authority (EFSA, 2010) a suitable indicator for occurrence and human exposure to ndl-PCBs. Therefore, it is appropriate to set maximum levels as a sum of these 6 PCBs. According to the Commission Regulation (EU) No., 1259/2011, there is no danger for human health by consuming this bivalve species, since contamination values among locations and age classes varied in the range of $0.1-2.3 \mathrm{ng} \cdot \mathrm{g}^{-1}$ wet weight, which is widely below the limit established for muscle meat of fish and fishery products ( $75 \mathrm{ng} \cdot \mathrm{g}^{-1}$ wet weight).

Although PCBs are present at low background levels, their harmful impact to human health after consumption over many years and after reaching a steady-state concentration in the body (bioaccumulation) is recognized. Thus, it is extremely important to determine the tolerable daily intake (TDI) for such contaminants. The French Food Safety Agency (AFSSA) and the Norwegian Scientific Committee for Food Safety (VKM) estimated a maximum permissible risk level, TDI for the sum of the six ecological indicator PCBs of $10 \mathrm{ng} \cdot \mathrm{kg}^{-1}$ body weight per day (AFSSA, 2007; VKM, 2008). Since there are no values in literature regarding gross consumption (GC) of shellfish in Portugal, it was reasonable to assume the GC calculated for bivalves in Italy $\left(2.3 \mathrm{~g} \cdot\right.$ day $\left.^{-1}\right)$ (Pompa et al., 2003), due to similarities in the Mediterranean diet common to both countries. Considering this average daily bivalve consumption, using a mean human body weight of 
$65 \mathrm{~kg}$ and the mean $\Sigma_{6} \mathrm{PCB}$ concentrations in S. plana from the Laranjo Bay $\left(0.93 \mathrm{ng} \cdot \mathrm{g}^{-1}\right.$ wet weight), the estimated $\Sigma_{6} \mathrm{PCB}$ daily intake for the Portuguese population would be $0.033 \mathrm{ng} \cdot \mathrm{kg}^{-1}$ body weight. Thus, the estimated daily intake does not exceed the established TDI and is inclusively about 300 times lower than that limit.

This research may have important implications for management policies and biomonitoring programs, by providing a better insight into the organochlorine bioaccumulation process in the bivalve $S$. plana, itself an important food resource for human population and a crucial contaminant transfer vehicle (biomagnification) to other economically important and exploited natural resources.

\section{Acknowledgments}

This research was supported by the FCT (Fundação para a Ciência e Tecnologia) through a PhD grant attributed to T.F. Grilo (SFRH/BD/ 44936/2008) and the MERCOAST project (PTDC/MAR/101906/2008), with funds from the POPH (Portuguese Operational Human Potential Program, the QREN Portugal (Portuguese National Strategic Reference Framework), and the MCTES (Portuguese Ministry of Science, Technology, and Higher Education). P. Pato acknowledges a postdoctoral fellowship from the FCT (SFRH/BPD/35068/2007). The authors are indebted to all their colleagues who assisted in the field and laboratory work and a special acknowledgment is addressed to Joana Baptista and Patrícia Matos who helped in methodological procedures.

\section{References}

AFSSA. Opinion of the French Food Safety Agency (AFSSA) on the establishment of relevant maximum levels for non dioxin-like polychlorobiphenyls (NDL-PCB) in some foodstuffs. AFSSA - Request No. 2006-SA-0305; 2007 [Maisons-Alfort].

Amodio E, Turci R, Massenti MF, Di Gaudio F, Minoia C, Vitale F, et al. Serum concentrations of persistent organic pollutants (POPs) in the inhabitants of a Sicilian city. Chemosphere 2012:89:970-4.

Antunes P, Gil O, Reis-Henriques MA. Evidence for higher biomagnification factors of lower chlorinated PCBs in cultivated seabass. Sci Total Environ 2007;377:36-44.

ATSDR. CERCLA Priority list of hazardous substances. Atlanta, GA: Agency for toxic substances and disease registry; 2007 [Available from: http://www.atsdr.cdc.gov/SPL/ index.html].

Bakke T, Källqvist T, Ruus A, Breedveld GD, Hylland K. Development of sediment quality criteria in Norway. J Soils Sediments 2010:10:172-8.

Baptista J, Pato P, Pereira E, Duarte AC, Pardal MA. PCBs in the fish assemblage of a southern European estuary. J Sea Res 2013;76:22-30.

Bazzanti M, Chiavarini S, Cremisini C, Soldati P. Distribution of PCB congeners in aquatic ecosystems: a case study. Environ Int 1997;23:799-813.

Bonnard M, Roméo M, Amiard-Triquet C. Effects of copper on the burrowing behavior of estuarine and coastal invertebrates, the polychaete Nereis diversicolor and the bivalve Scrobicularia plana. Hum Ecol Risk Assess 2009;15:11-26.

Brey T. Population dynamics in benthic invertebrates. A virtual handbook. Version 01.2. Germany: Alfred Wegener Institute for Polar and Marine Research; 2001 [Available from: http://www.awibremerhaven.de/Benthic/Ecosystem/FoodWeb/Handbook/ main.html].

Cailleaud K, Forget-Leray J, Souissi S, Hilde D, LeMenach K, Budzinski H. Seasonal variation of hydrophobic organic contaminants concentrations in the water column of the Seine Estuary and their transfer to a planktonic species Eurytemora affinis (Calaïnoda, Copepoda). Part 1: PCBs and PAHs. Chemosphere 2007;70:270-80.

Cardoso PG, Pereira E, Grilo TF, Duarte AC, Pardal MA. Kinetics of mercury bioaccumulation in the polychaete Hediste diversicolor and in the bivalve Scrobicularia plana, through a dietary exposure pathway. Water Air Soil Pollut 2012;223:421-8.

Cardoso PG, Grilo TF, Pereira E, Duarte AC, Pardal MA. Mercury bioaccumulation and decontamination kinetics in the edible cockle Cerastoderma edule. Chemosphere 2013:90:1854-9.

Carro N, García I, Ignacio M, Mouteira A. Spatial and temporal trends of PCBs (polychlorinated biphenyls) in mussel from Galician coast (1998-2008). Environ Int 2010;36:873-9.

Castells P, Parera J, Santos FJ, Galceran MT. Occurrence of polychlorinated naphthalenes, polychlorinated biphenyls and short chain chlorinated paraffins in marine sediments from Barcelona (Spain). Chemosphere 2008;70:1552-62.

CCME, Canadian Council of Ministers of the Environment. Canadian sediment quality guidelines for the protection of aquatic life: summary tables. Updated. Canadian environmental quality guidelines, 1999, Canadian Council of Ministers of the Environment, Winnipeg; 2002. [Available from: http://www.ecy.wa.gov/programs/eap/ psamp/BoundaryBay/PSAMP-BBAMP\%20documents/Canadian\%20guidelines\%20for\% 20water\%20quality/SedimentProtAquaticLifeSummaryTables(en).pdf].

Chen M-Y, Yu M, Luo X-J, Chen S-J, Mai B-X. The factors controlling the partitioning of polybrominated diphenyl ethers and polychlorinated biphenyls in the watercolumn of the Pearl River Estuary in South China. Mar Pollut Bull 2011;62:29-35.
Coelho JP, Rosa M, Pereira E, Duarte A, Pardal MA. Pattern and annual rates of Scrobicularia plana mercury bioaccumulation in a human induced mercury gradient (Ria de Aveiro, Portugal). Estuar Coast Shelf Sci 2006;69:629-35.

Commission Regulation (EU) No 1259/2011 of 2 December 2011 amending Regulation (EC) No 1881/2006 as regards maximum levels for dioxins, dioxin-like PCBs. Available from (http://eur-lex.europa.eu/LexUriServ/LexUriServ.do?uri=OJ:L:2011:320:0018: 0023:EN:PDF).

Decreto-Lei no. 226-A/2007, 31 May; Portaria no. 1450/2007, 12 November. Available from: http://dre.pt/pdf1sdip/2007/11/21700/0837208382.pdf.

Dolbeth M, Lillebø AI, Cardoso PG, Ferreira SM, Pardal MA. Annual production of estuarine fauna in different environmental conditions: an evaluation of the estimation methods. J Exp Mar Biol Ecol 2005;326:115-27.

Dolbeth M, Cardoso PG, Grilo TF, Bordalo MD, Raffaelli D, Pardal MA. Long-term changes in the production by estuarine macrobenthos affected by multiple stressors. Estuar Coast Shelf Sci 2011:92:10-8.

European Food Safety Authority (EFSA) Journal 2010; 8 (7): 1701. Available from: http://www.efsa.europa.eu/en/efsajournal/doc/1701.pdf.

Fang ZQ. Organochlorines in sediments and mussels collected from coastal sites along the Pearl River Delta, South China. J Environ Sci 2004:16:321-7.

Fouial-Djebbar D, Djebbar R, Yacine A, Badjah-Hadj-Ahmed AY, Budzinski H. Level of polychlorinated biphenyls in marine environment of Algiers Bay, Algeria. Anal Lett 2011:44:2438-56

He M-c, Sun Y, Sun Y, Li X-r, Yang Z-f. Distribution patterns of nitrobenzenes and polychlorinated biphenyls in water, suspended particulate matter and sediment from mid- and down-stream of the Yellow River (China). Chemosphere 2006;65:365-74.

Hillebrand MTHJ, Everaarts JM, Razak H, Moelyadi Moelyo D, Stolwijk L, Boon JP. Input of selected chlorinated hydrocarbons into the coastal area of east Java and adjacent waters: distribution patterns in the dissolved and suspended phase. Neth J Sea Res 1989:23:369-77.

ICES. Guidelines for temporal trend analysis of data on contaminants in shellfish Report of the ICES Advisory Committee on marine pollutionCooperative research reports; 1987. [142 pp.].

International Atomic Energy Agency, Marine Environment Laboratory - MESL, Report IAEA/AL/121 (IAEA/MEL/67). Worldwide and regional intercomparison for the determination of organochlorine compounds, petroleum hydrocarbons and sterols in the sediment sample IAEA-408, Monaco; 1999.

Khaled A, El Nemr A, Said TO, El-Sikaily A, Abd-Allah AMA. Polychlorinated biphenyls and chlorinated pesticides in mussels from the Egyptian Red Sea coast. Chemosphere 2004;54:1407-12.

Kim KS, Lee SC, Kim KH, Shim WJ, Hong SH, Choi KH, et al. Survey on organochlorine pesticides, PCDD/Fs, dioxin-like PCBs and HCB in sediments from the Han River, Korea. Chemosphere 2009;75:580-7.

Lee $\mathrm{H}$. Models, muddles, and mud: predicting bioaccumulation of sediment associated pollutants. In: Burton AG, editor. Sediment toxicity assessment. Boca Raton, FL: CRC; 1992. p. 267-93.

Lobo J, Costa PM, Caeiro S, Martins M, Ferreira AM, Caetano M, et al. Evaluation of the potential of the common cockle (Cerastoderma edule L.) for the ecological risk assessment of estuarine sediments: bioaccumulation and biomarkers. Ecotoxicology 2010;19:1496-512.

Maldonado C, Bayona JM. Organochlorine compounds in the north-western Black Sea water: distribution and water column processes. Estuar Coast Shelf Sci 2002;54: 527-40.

OSPAR. Quality status report 2010. OSPAR commission; 2010 [London, 176 pp.]

Otchere FA. Organochlorines (PCBs and pesticides) in the bivalves Anadara (Senilis) senilis, Crassostrea tulipa and Perna perna from the lagoons of Ghana. Sci Total Environ 2005;348:102-14.

Pereira ME, Lillebø AI, Pato P, Válega M, Coelho JP, Lopes CB, et al. Mercury pollution in Ria de Aveiro (Portugal): a review of the system assessment. Environ Monit Assess 2009;155:39-49.

Piérard C, Budzinski H, Garrigues P. Grain-size distribution of polychlorobiphenyls in coastal sediments. Environ Sci Technol 1996;30:2776-83.

Pompa G, Caloni F, Fracchiolla ML. Dioxin and PCB contamination of fish and shellfish: assessment of human exposure. Review of the international situation. Vet Res Commun 2003;27:159-67.

Quental T, Ferreira AM, Vale C. The distribution of PCBs and DDTs in seston and plankton along the Portuguese coast. Acta Oecol 2003;24:S333-9.

Ritter L, Solomon K, Forget J. A review of selected persistent organic pollutants: DDTaldrin-dieldrin-endrin-chlordane-heptachlor-hexachlorobenzene-mirex-toxaphenepolychlorinated biphenyls-dioxins-furans. The International Programme on Chemical Safety (IPSC) within the framework of the Inter-Organization Programme for the Sound Management of Chemicals (IOMC); 1995 [149 pp.].

Strandberg B, Bandh C, van Bavel B, Bergqvist PA, Broman D, Ishag R, et al. Organochlorine compounds in the Gulf of Bothnia: sediment and benthic species. Chemosphere 2000;40:1205-11.

Tomza A, Witczak A, Ciereszko W. Uptake of polychlorinated biphenyls in freshwater mussels Anodonta complanata from the lower Odra river. Pol J Environ Stud 2006;15:603-8.

UNEP. Stockholm Convention. Final act of the conference of plenipotentiaries on the Stockholm convention on persistent organic pollutants; 2001 [Geneva, Switzerland, 44 pp.].

United States Environmental Protection Agency (USEPA). CRITFC exposure study. Water quality criteria and standards newsletter. Washington, DC: USEPA; 1995.

United States Environmental Protection Agency (USEPA). Method 3540C: Soxhlet extraction. Washington, DC: US Environmental Protection Agency; 1996.

United States Environmental Protection Agency (USEPA). EPA Method 3510C: Separatory funnel liquid-liquid extraction. Report number: SW-846 Ch 4.2.1. 
Available from: http://www.caslab.com/EPA-Methods/PDF/EPA-Method-3510C. pdf.

Verdelhos T, Neto JM, Marques JC, Pardal MA. The effect of eutrophication abatement on the bivalve Scrobicularia plana. Estuar Coast Shelf Sci 2005;63:261-8.

Vieweg I, Hop H, Brey T, Huber S, Ambrose Jr WG, Locke VWL, et al. Persistent organic pollutants in four bivalve species from Svalbard waters. Environ Pollut 2012;161:134-42.

Villeneuve J-P, Cattini C, Bajet CM, Navarro-Calingacion MF, Carvalho FP. PCBs in sediments and oysters of Manila Bay, the Philippines. Int J Environ Health Res 2010;20:259-69.

VKM. Opinion of the Panel on Contaminants of the Norwegian Scientific Committee for Food Safety. Risk assessment of non dioxin-like PCBs in Norwegian food; 2008 [Available from: http://www.vkm.no/dav/c29e178d9c.pdf].

Wang Y, Wang T, Li A, Fu J, Wang P, Zhang Q et al. Selection of bioindicators of polybrominated diphenyl ethers, polychlorinated biphenyls, and organochlorine pesticides in mollusks in the Chinese Bohai Sea. Environ Sci Technol 2008;42:7159-65.
Winer BJ, Brown DR, Michels KM. Statistical principles in experimental design. 3rd ed. New York: McGraw-Hill; 1991.

Wu WZ, Schramm KW, Henkelmann B, Xu Y, Yediler A, Kettrup A. PCBs, HCHs and HCB in sediments and soils of Ya-Er Lake area in China: results on residual levels and correlation to the organic carbon and the particle size. Chemosphere 1997;24: 191-202.

Wurl O, Obbard JP. Distribution of organochlorine compounds in the sea-surface microlayer, water column and sediment of Singapore's coastal environment. Chemosphere 2006;62:1105-15.

Zar J. Biostatistical analysis. 3rd ed. Upper Saddle River, NJ: Prentice-Hall; 1996.

Zhou JL, Maskaoui K, Qiu YW, Hong HS, Wang ZD. Polychlorinated biphenyl congeners and organochlorine insecticides in the water column and sediments of Daya Bay, China. Environ Pollut 2001;113:373-84. 